\title{
FUNCTIONAL OUTCOME OF ARTHROSCOPIC ANTERIOR CRUCIATE LIGAMENT RECONSTRUCTION WITH HAMSTRING AUTO GRAFT
}

\author{
Sadhana P1, Unnam Arjun Kumar², David Raju
}

${ }_{1}^{1}$ Senior Resident, Department of Orthopaedics, King George Hospital, Vishakhapatnam, Andhra Pradesh, India.

${ }^{2}$ Senior Resident, Department of Orthopaedics, Srinivas Institute of Medical Sciences and Research Centre, Mukka, Karnataka, India. 3Professor, Department of Orthopaedics, Maharaja Institute of Medical Sciences, Vizayanagarm, Andhra Pradesh, India.

\section{ABSTRACT}

\section{BACKGROUND}

Arthroscopic Anterior cruciate ligament reconstruction is most common surgery in orthopaedic practice. Various types of grafts are available for reconstruction, hamstring tendon graft is commonly used with excellent results. The aim of this study was to evaluate the functional outcome of arthroscopic anterior cruciate ligament reconstruction by quadrupled single bundle hamstring graft through accessory anteromedial portal by clinical outcome score international knee documentation committee (IKDC).

\section{MATERIALS AND METHODS}

A prospective study was done. 30 patients were included in the study based on inclusion and exclusion criteria. All patients underwent arthroscopic anterior cruciate ligament reconstruction with autogenous hamstring tendon graft. All patients were followed up according to postoperative rehabilitation protocol. At final follow up functional assessment was done according to IKDC.

\section{RESULTS}

All cases were males, majority of the patients belonged to 20-30 years age group. The most common cause was sports injuries $(53.33 \%)$ followed by road traffic accidents $(26.66 \%) .100 \%$ patients presented with giving way of the knee. Clicking of knee was appreciated in $66.66 \%$. Swelling and pain was seen in $60 \%$ patients. According to IKDC score postoperative recovery as normal was seen in $90 \%$ patients whereas 3 patients $(10 \%)$ graded recovery as abnormal.

\section{CONCLUSION}

Arthroscopic ACL reconstruction with autogenous hamstring graft gives high success rate in view of functional outcome.

\section{KEY WORDS}

Anterior Cruciate Ligament, IKDC Score.

HOW TO CITE THIS ARTICLE: Sadhana P, Kumar UA, Raju SD. Functional outcome of arthroscopic anterior cruciate ligament reconstruction with hamstring auto graft. J. Evolution Med. Dent. Sci. 2019;8(06):394-398, DOI: 10.14260/jemds/2019/87

\section{BACKGROUND}

Knee joint injuries plays a major role in many popular knee pivoting sports including soccer, basketball, skiing etc. ${ }^{1}$ In the past 20 years Anterior Cruciate Ligament (ACL) injury has been studied extensively. It is more common than the posterior cruciate ligament injury. Due to poor capacity to repair ACL, patients who have knee symptoms related to ACL deficiency may consider ligament reconstruction as a means of stabilizing the tibio-femoral joint and restoring high-level function of the knee joint. Nearly $40 \%$ of all knee injury problems are related to ligamentous injury, and isolated ACL injury constitutes nearly $50 \%$ of all knee ligament injuries. ${ }^{2,3,4}$

Approximately 3,00,000 ACL reconstructions are performed in the USA alone each year ${ }^{5}$. Various types of grafts used for ACL reconstruction like auto graft (Quadriceps tendon patellar tendon, hamstring tendon) and allograft (Patellar, hamstring, achilles or tibialis anterior) tendons.

'Financial or Other Competing Interest': None.

Submission 01-12-2018, Peer Review 25-01-2019,

Acceptance 31-01-2019, Published 11-02-2019.

Corresponding Author:

Unnam Arjun Kumar,

Flat No. 405, Shambavi Empire,

Vidyaratna Nagar,

Manipal-576104, Karnataka, India.

E-mail: arjunampr8@gmail.com

DOI: $10.14260 /$ jemds/2019/87

\section{(c) $(1)(5)$}

Some surgeons use silver wire, fascia lata, ${ }^{6}$ and Iliotibial band $^{7}$ for ACL reconstruction. ACL reconstruction with hamstring tendon is becoming increasingly popular in patients with symptomatic instability and in appropriately selected patients can yield successful and satisfactory results. ${ }^{8}$ Arthroscopically assisted ACL reconstruction has the advantage of being minimally invasive, accurate graft placement, less disturbance of normal tissue resulting in quicker recovery and rehabilitation, less infection rate, minimal hospital stay.

This study aimed to assess the outcome of arthroscopic ACL reconstruction using semitendinosus auto graft at our Centre using IKDC score.

\section{MATERIALS AND METHODS}

This study was a prospective study. Study was conducted in Maharaja Institute of Medical Sciences, Nellimarla, Vizianagaram, 30 cases were included in the study according to inclusion and exclusion criteria and treated from January 2016 to June 2017 and all patients were followed up according to postoperative protocol.

\section{Inclusion Criteria}

1. Complete ACL tear confirmed by MRI requiring primary ACL reconstruction.

2. Radiographic evidence of skeletal maturity; patient between 15 and 55 years of age. 


\section{Exclusion Criteria}

1. Anterior cruciate ligament tear of less than 3 weeks.

2. Anterior cruciate ligament tear associated with other ligament injuries (Posterior cruciate ligament tear, collateral ligament injuries and postero-lateral corner).

3. Anterior cruciate ligament tear associated with bony injury around the knee.

4. Patients with ACL avulsion injury.

\section{Surgical Procedure}

Under strict aseptic conditions, patient is in supine position, initial diagnostic arthroscopy done. ACL tear was found and remaining PCL, MM, LM, MCL, LCL were found normal. Remnant ACL stem was shaved off. Now semi tendinosis and Gracilis graft was collected and prepared. Later appropriate size measured, and graft inserted through tibial and femoral tunnel using zigs and fixed with titanium screws of appropriate size. Wound closed after through lavage and compression bandage applied.

\section{RESULTS}

Our study included a total of 30 patients with mean age group of 29.6 years and majority of patients being $26-30$ years (40\%) followed by 21-25 yrs. (23.34\%) with all patients being males. This male predominance could be attributed to their active involvement in sports, farming and road traffic accidents. Sports activities like football, kabaddi and athletics like jumping, police physical training, etc (53.33\%) were the most common cause and next most common is road traffic accidents (26.66\%). Some patients (20\%) has fall while walking/ climbing down stairs. Giving way of the knee seen in $100 \%$ patients. Clicking of knee seen in $66.66 \%$, swelling associated with pain seen in $60 \%$ cases. $46.66 \%$ gave history of locking of knee which was correlated with associated injuries in the knee. Medial meniscal tear was the commonest associated injury (36.67\%) detected by MRI followed by lateral meniscus (26.67\%). Their postoperative recovery was normal in 57\% and near normal in 33\%. The abnormal group included three patients with 1 superficial infection, 1 with laxity and 1 with FFD. Pre-injury level achieved in $87 \%$ of patients, but 4 patients were noncompliant to protocol.

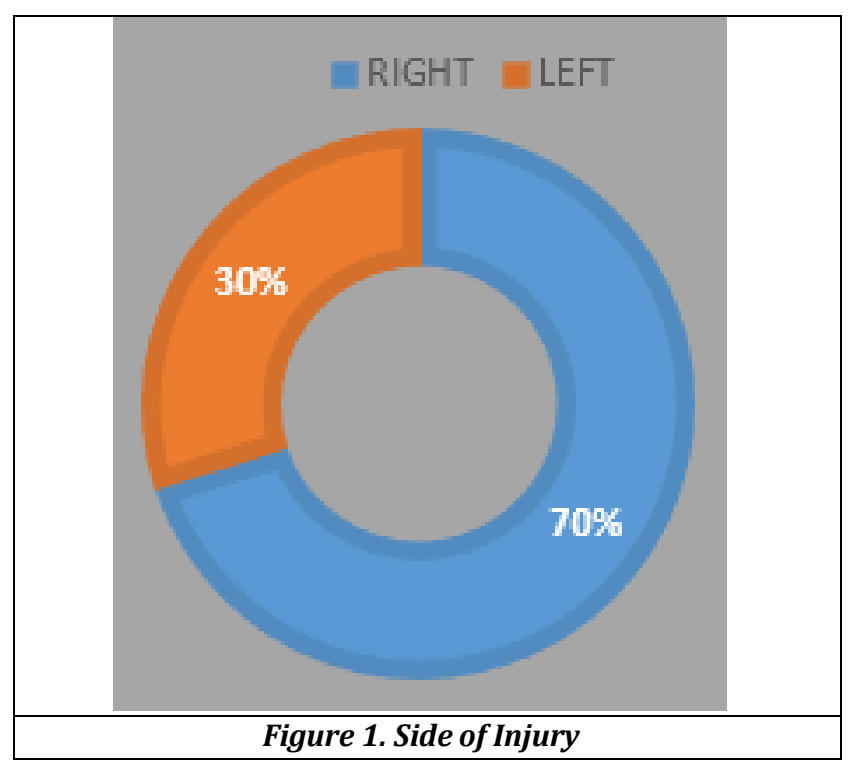

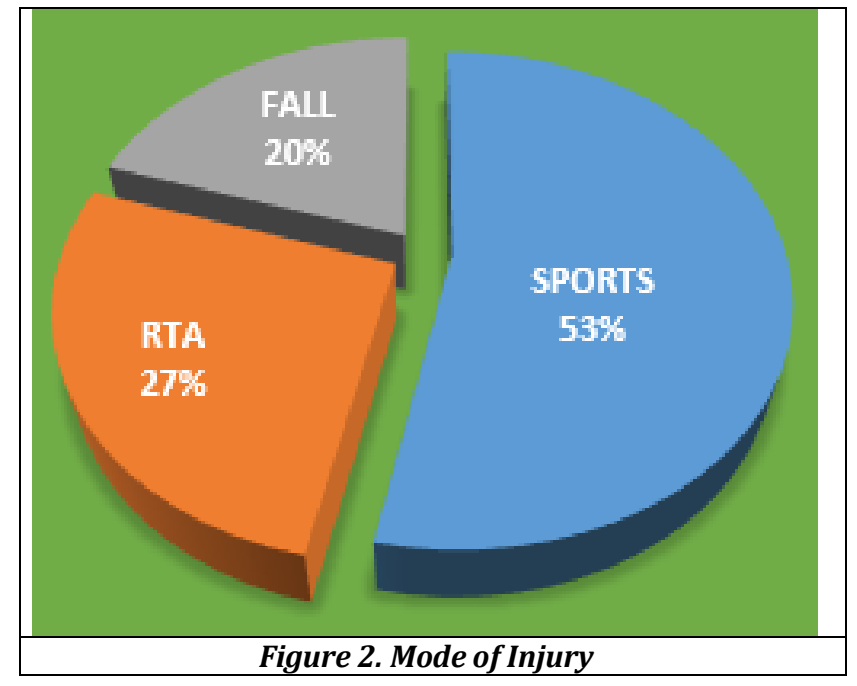
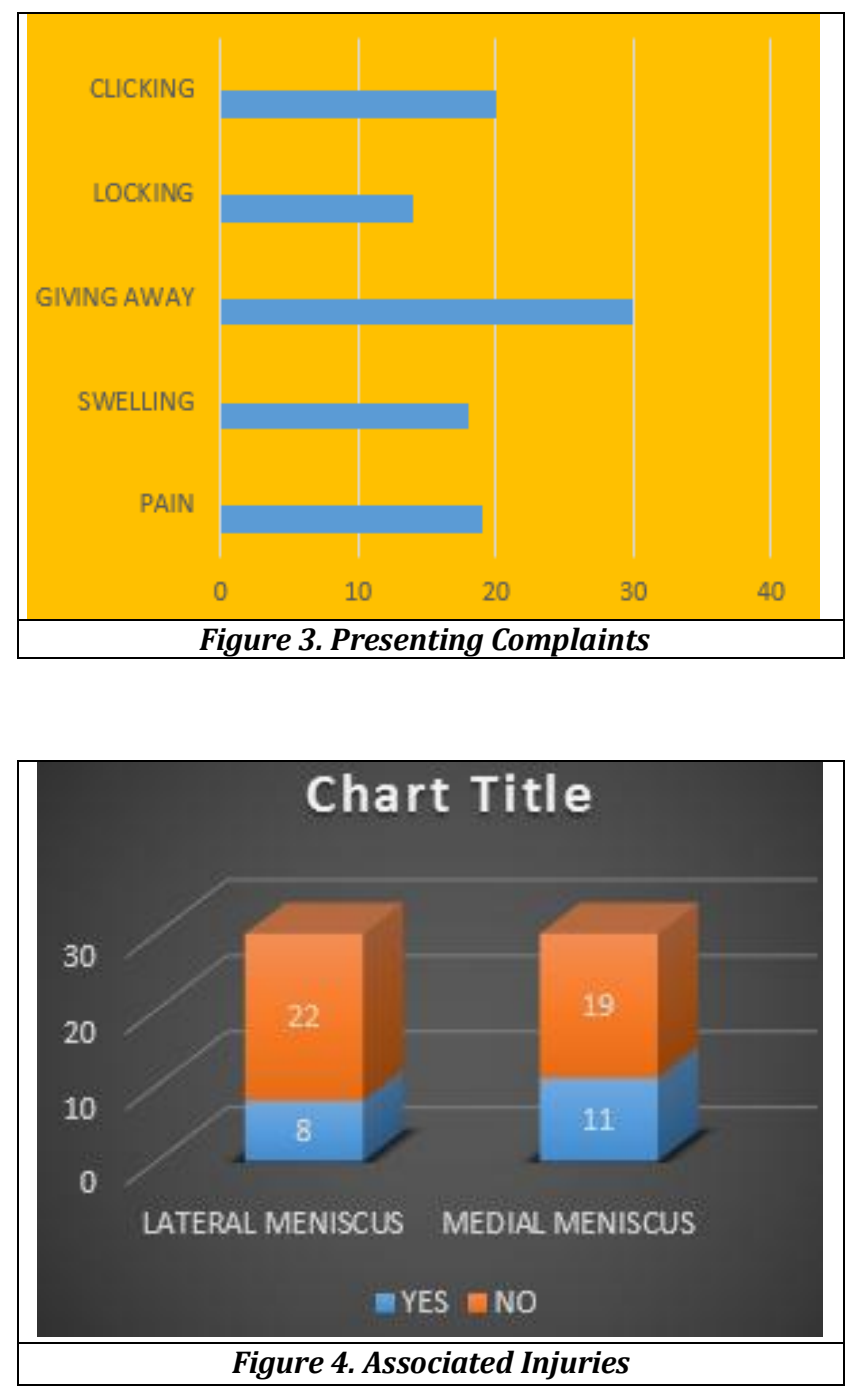

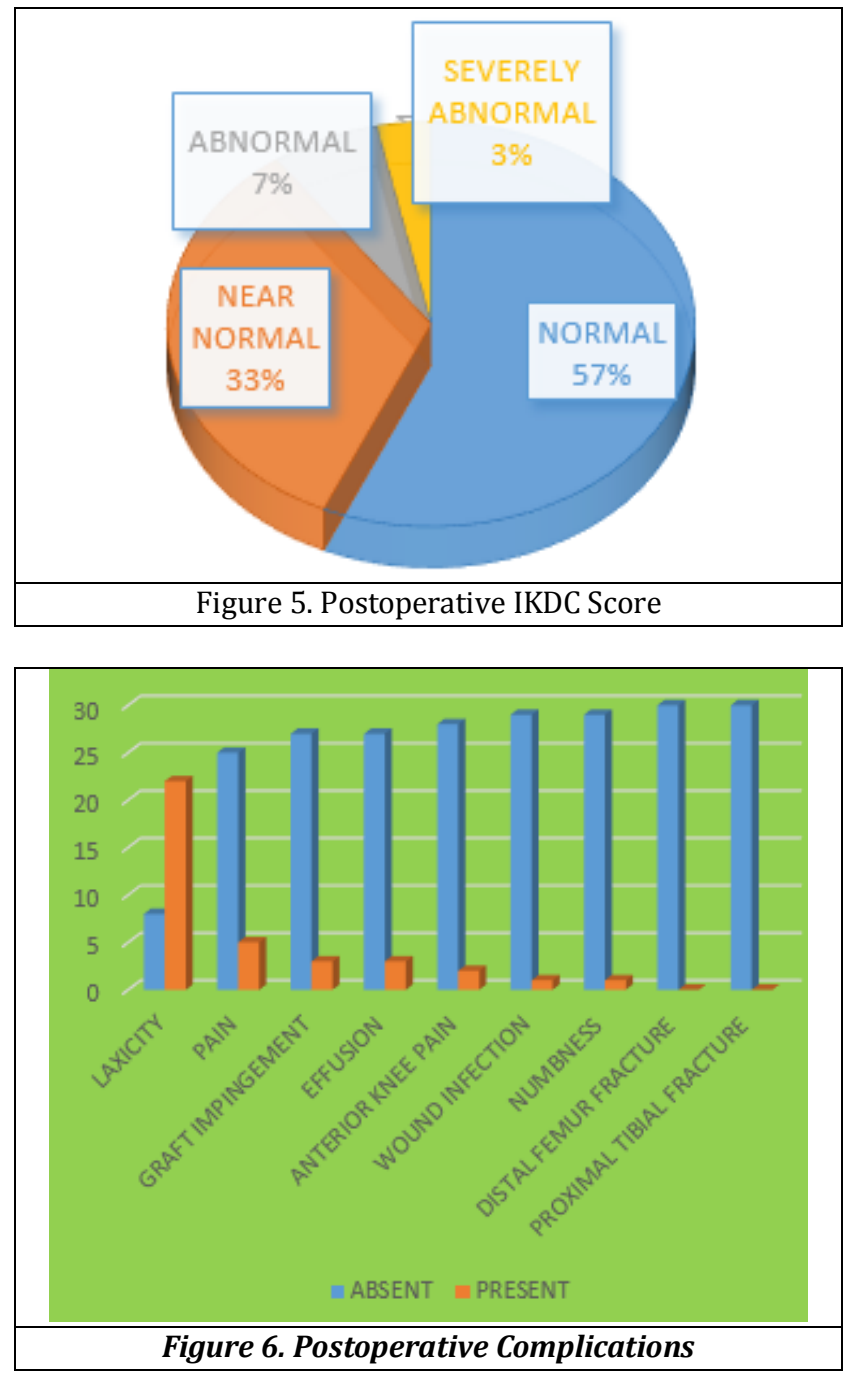

\section{Clinical Photographs}

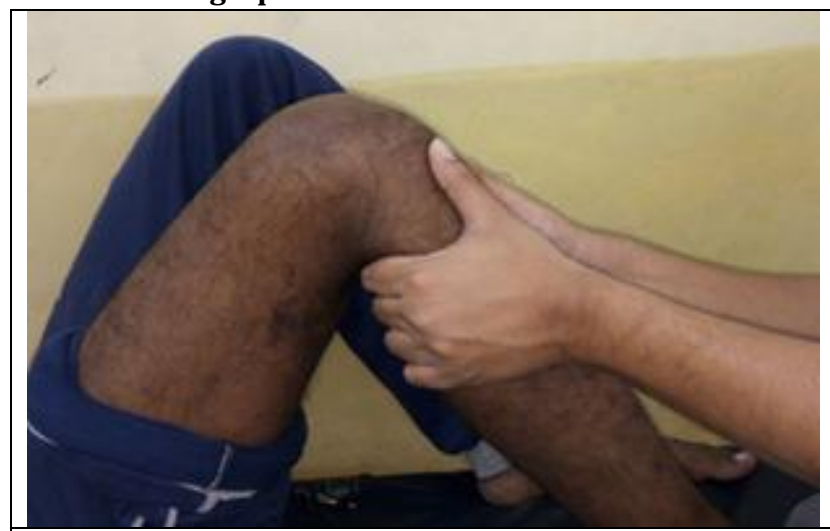

Figure 7. Anterior Drawers Test

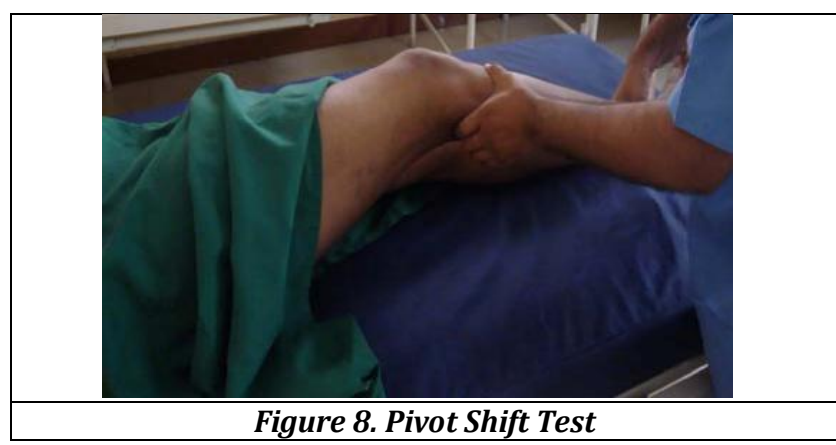

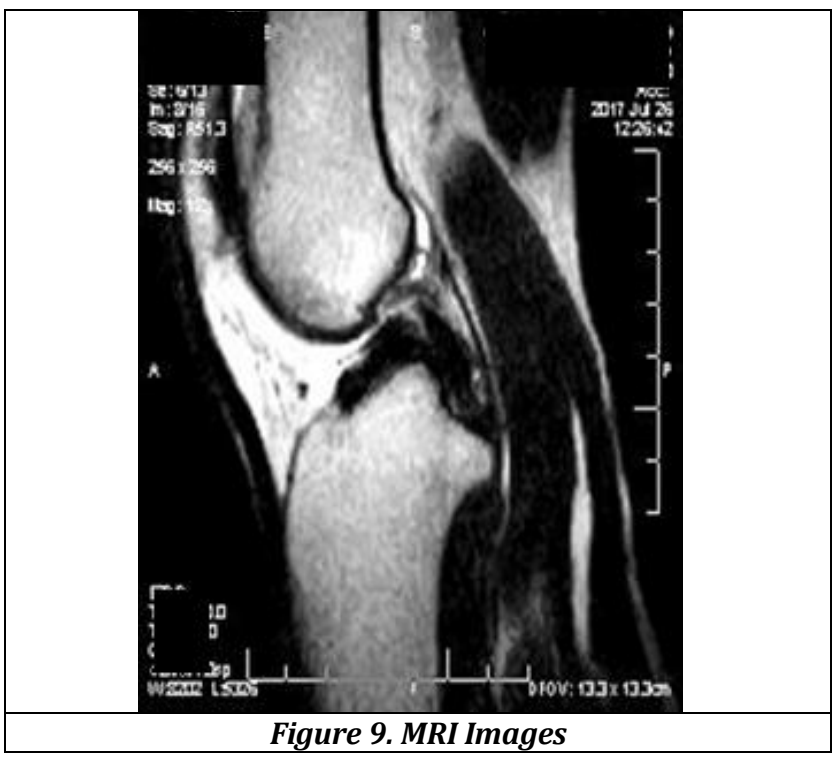
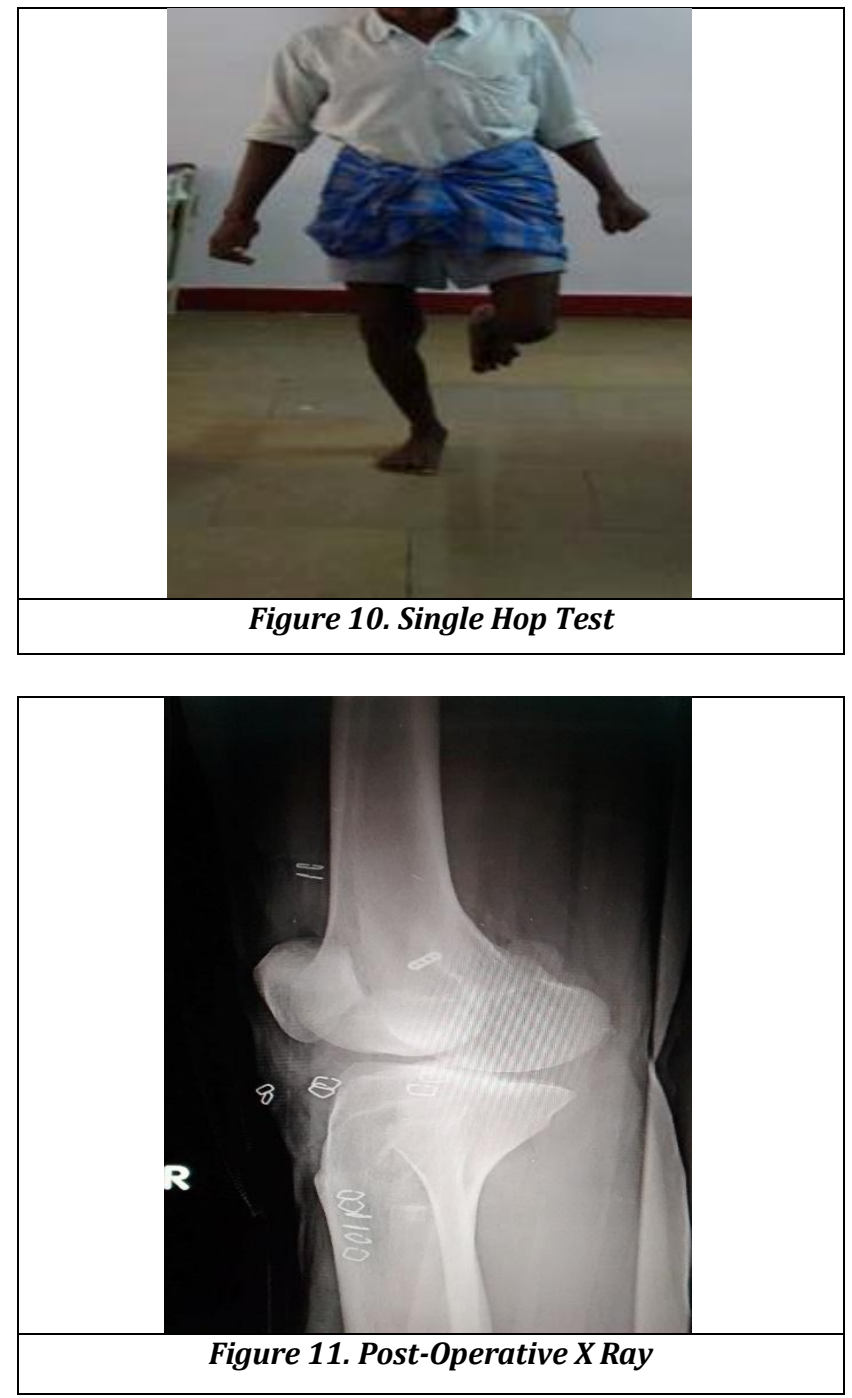

\section{DISCUSSION}

Anterior cruciate ligament (ACL) tears can lead to subsequent knee disability, with potentially devastating long-term consequences which can be severe enough interfering with day to day daily activities. With improving results and increasingly reliable outcomes. Patient and physician expectations have evolved to include the goal of return to activities and sports to pre-injury level at normal or near 
normal levels. Physiotherapy and rehabilitation programmes are used after ACL reconstruction surgery. These programmes are designed to maximize function by increasing the strength, improving range of motion, and neuromuscular coordination. Less donor site morbidity associated with hamstring graft than that of patellar bone- tendon- bone grafts and carries no risk of patellar fractures.

Various options of grafts available for ACL repair, but hamstring auto grafts have increasingly become more popular over the past decade. Multiple-strand hamstring tendon ACL reconstructions have higher strength, stiffness, and cross-sectional area compared with patellar tendon grafts. Stable initial graft fixation is required for a successful ACL reconstruction using hamstring autograft and, ultimately, graft- to- bone healing. Hamstring reconstruction using femoral endo button fixation has been shown to have excellent initial mechanical properties, including pull out strength. Tibial fixation is done with interference screw. Maurilio Marcacci et al study, out of fifty patients 40 were men and 10 were women. ${ }^{9}$ Vassilios S Nikolaou et al study, there are 30 males and 16 females among 46 patients with ACL injuries. ${ }^{10}$ Our study all 30 patients were male. Brown et al study mean subject age was $28.8+/-12.8$ years ${ }^{11}$. Maurilio Marcacci et al study, mean age was 28 years, ranging from 1839 years. ${ }^{9}$ Vassilios $S$ Nikolaou et al study, the mean age was $32(18-45)$ years. ${ }^{10}$ Our study mean age was 27.66 years. (15-45 years).

Vassilios S Nikolaou et al, in June 2008, after a retrospective analysis of MRI efficiency in diagnosing internal lesions of the knee, reported that the accuracy for tears to the medial, lateral meniscus, anterior and posterior cruciate ligaments and articular cartilage was $81 \%, 77 \%, 86 \%$, 98\% and $60 \%$ respectively. ${ }^{10}$ They concluded that MRI is very helpful in diagnosing meniscal and cruciate ligament injuries and found that the clinical examination had significant lower reliability in the detection of these injuries. But its importance is still vague in a countable percentage reports with false results and in chondral defects. The arthroscopy still remains the gold standard for definitive diagnosis. Clinical evaluation of the patients for instability was an essential component in our study. In our study, MRI showed complete Anterior Cruciate Ligament tear in all patients and Medial meniscus was most commonly associated followed by Lateral Meniscus which correlated with arthroscopy with accuracy more than $90 \%$. So in our study, as MRI may help to look out for other lesions and repair them, we conclude that MRI is preferable to arthroscopy before surgery, which improves clinical outcome of the patients. In Vassilios S Nikolaou et al study, there are 29 Medial meniscus tears, 21 Lateral meniscus tears, 23 isolated ACL injuries and 3 PCL injuries noticed during arthroscopy. In our study there are 11 Medial meniscus tears, 8 Lateral meniscus tears, 11 isolated ACL injuries and no PCL injuries in arthroscopy.

In 2003, Fareed $\mathrm{H}$ et al reported the results of a retrospective study on patients who underwent arthroscopic ACL reconstruction ${ }^{12}$. The purpose of their study was to evaluate their initial experience with this procedure. Between July 97 and March 2001, 29 patients underwent arthroscopic ACL reconstruction with 4 strand hamstring tendon graft. 25 were available for follow up. Same rehabilitative program was followed by all the patients. IKDC ligament evaluation system used for evaluation. Button $\mathrm{K}^{13}$ and others, in 2005 , evaluated the outcome of ACL reconstruction with semitendinosus tendon autograft with same rehabilitation protocol in 48 patients at 20 months.

\begin{tabular}{|c|c|c|c|}
\hline & $\begin{array}{c}\text { Fareed H12 } \\
\text { et al (2003) }\end{array}$ & $\begin{array}{c}\text { K Button \& } \\
\text { Others } \\
(\mathbf{2 0 0 5 )}\end{array}$ & $\begin{array}{c}\text { Present } \\
\text { Study }\end{array}$ \\
\hline No. of Patients & 25 & 48 & 30 \\
\hline $\begin{array}{c}\text { Average } \\
\text { Follow Up }\end{array}$ & 25.4 Weeks & 20 Weeks & 24 Weeks \\
\hline IKDC Normal & $12(48 \%)$ & $26(54 \%)$ & $17(56.66 \%)$ \\
\hline Near Normal & $12(48 \%)$ & $18(38 \%)$ & $10(33.33 \%)$ \\
\hline Abnormal & $01(4 \%)$ & $04(8 \%)$ & $03(10 \%)$ \\
\hline Table 1. Comparison of Our Study with Fareed H et al \\
and K Button \& Others \\
\hline
\end{tabular}

\begin{tabular}{|c|c|c|c|}
\hline & \begin{tabular}{|c|} 
Andrea reid 14 \\
et al. Study, \\
2007
\end{tabular} & $\begin{array}{l}\text { Gulick TD } \\
\text { Study, } 2002\end{array}$ & $\begin{array}{l}\text { Present } \\
\text { Study }\end{array}$ \\
\hline $\begin{array}{l}\text { Number of } \\
\text { Patients }\end{array}$ & 42 & 57 & 30 \\
\hline Average Age & 26 Years & 27 Years & 29 Years \\
\hline $\begin{array}{l}\text { Rehabilitation } \\
\text { Protocol }\end{array}$ & $\begin{array}{c}4-6 \\
\text { Months }\end{array}$ & $\begin{array}{c}4-6 \\
\text { Months }\end{array}$ & $\begin{array}{c}4-6 \\
\text { Months }\end{array}$ \\
\hline $\begin{array}{l}\text { Hop Test- Mean } \\
\text { Limb Symmetry }\end{array}$ & $\begin{array}{c}88.2+/-9.5 \\
(63.8-103.2) \\
\text { At } 22 \text { Weeks }\end{array}$ & - & $\begin{array}{c}83.503+/- \\
3.65 \\
(66.36- \\
93.33) \text { At } 24 \\
\text { Weeks }\end{array}$ \\
\hline $\begin{array}{c}\text { Laxity } \\
\text { Up to Grade } 1\end{array}$ & $72 \%$ & $74.6 \%$ & $76.67 \%$ \\
\hline $\begin{array}{l}\text { Return to Prior } \\
\text { of Function }\end{array}$ & - & $84 \%$ & $86.67 \%$ \\
\hline \multicolumn{4}{|c|}{$\begin{array}{l}\text { Table 2. Andrea Reid et al \& Gulick TD \& Our Study } \\
\text { Comparison }\end{array}$} \\
\hline
\end{tabular}

\begin{tabular}{|c|c|c|c|}
\hline & $\begin{array}{c}\text { Paolo Aglietti } \\
\text { et al Study15 }\end{array}$ & $\begin{array}{c}\text { Kyung- } \\
\text { Wook Nha } \\
\text { et al } \\
\text { Study }\end{array}$ & $\begin{array}{c}\text { Present } \\
\text { Study }\end{array}$ \\
\hline Normal & 37 & 42 & 17 \\
\hline Near Normal & 25 & 13 & 10 \\
\hline Abnormal & 3 & 0 & 2 \\
\hline Severely Abnormal & 4 & 0 & 1 \\
\hline Total & $\mathbf{6 9}$ & $\mathbf{5 5}$ & $\mathbf{3 0}$ \\
\hline \multicolumn{2}{|c|}{ Table 3. Post-Operative Outcome IKDC Scoring }
\end{tabular}

In Andrew D Lynch et al study, ${ }^{17}$ there is absence of giving away in $96.6 \%, 84.1 \%$ have absence of joint effusion, $91.1 \%$ returned to sports and there is laxity in $72.9 \%$ patients who has been operated. In present study no patient had postoperative giving away, $90 \%$ have no joint effusion, $87 \%$ returned to sports activities, 4 patients (13.33\%) had pain at the graft donor site. Numbness around graft site seen in one patient but resolved gradually. Superficial skin infection seen in two patients and resulting in delayed wound healing.

\section{CONCLUSION}

ACL reconstruction with quadrupled semitendinosus graft has high success rate with good functional results. MRI is very helpful in diagnosing meniscal injuries, cruciate ligament injuries and extra articular ligament injuries like medial and lateral collateral ligaments and is also helpful in planing surgery. 


\section{REFERENCES}

[1] Van Kampen A. The knee joint in sports medicine. International Orthopaedics (SICOT) 2013;37(2):177-9.

[2] Nicholl JP, Coleman P, Williams BT. Pilot study of the epidemiology of sports injuries and exercise related morbidity. Br J Sports Med 1991;25(1):61-6.

[3] Miyasaka KC, Daniel DM, Stone ML, et al. The incidence of knee ligament injuries in the general population. Am J Knee Surg 1991;4:3-8.

[4] Bollen S. Epidemiology of knee injuries: diagnosis and triage. Br J Sports Med 2000;34(3):227-8.

[5] Chechik 0, Amar E, Khashan M, et al. An international survey on anterior cruciate ligament reconstruction practices. Int Orthop 2013;37(2):201-6.

[6] Hey-Groves EW. The crucial ligaments of the knee joint: their function, rupture and the operative treatment of the same. Br J Surg 1920; 7:505-15.

[7] Smith MSA. The diagnosis and treatment of injuries to the crucial ligaments. Br J Surg 1918;6(22):176-89.

[8] Khan RM, Prasad V, Gangone R, et al. Anterior cruciate ligament reconstruction in patients over 40 yrs using hamstring autograft. Knee Surgery Sports Traumatology Arthroscopy 2010;18(1):68-72.

[9] Marcacci M, Zaffagnini S, Iacono F, et al. Intra- and extraarticular anterior cruciate ligament reconstruction utilizing autogeneous semitendinosus and gracilis tendons: 5-year clinical results. Knee Surg Sports Traumatol Arthrosc 2003;11(1):2-8.

[10] Nikolaou VS, Chromopoulos E, Savvidou C, et al. MRI efficacy in diagnosing internal lesions of knee: a retrospective analysis. J Trauma Management \& Outcomes 2008;2(1):4.
[11] Brown TN, Palmieri Smith RM, Mclean SG. Sex and limb differences in hip and knee kinematics and kinetics during anticipated and unanticipated jump landings: implications for anterior cruciate ligament injury. Br J Sports Med 2009;43(13):1049-56.

[12] Fareed H, Dionellis P, Paterson FWN. Arthroscopic ACL reconstruction using 4 strand hamstring tendon graft. J Bone Join Surg 2003;85B:231-6.

[13] Gulick TD, Yoder HN. Anterior cruciate ligament reconstruction: clinical outcomes of patella tendon and hamstring tendon gifts. J Sports Science and Medicine 2002;1(3):63-71.

[14] Reid A, Birmingham TB, Stratford PW, et al. Hop testing provides a reliable and valid outcome measure during rehabilitation after anterior cruciate ligament reconstruction. Physical Therapy 2007;87(3):337-49.

[15] Aglietti P, Buzzi R, Menchetti PM, et al. Arthroscopically assisted semitendinosus and gracilis tendon graft in reconstruction for acute anterior cruciate ligament injuries in athletes. Am J Sports Med 1996;24(6):726-31.

[16] Nha KW, Han JH, Kwon JH, et al. Anatomical singlebundle anterior cruciate ligament reconstruction using a freehand transtibial technique. Knee Surg Relat Res 2015;27(2):117-22.

[17] Lynch AD, Logerstedt DS, Grindem H, et al. Consensus criteria for defining 'successful outcome' after ACL injury and reconstruction: a Delaware-Oslo ACL cohort investigation. Br J Sports Med 2015;49(5):335-42. 